\title{
REVIEW
}

\section{Review of social services on the vulnerable population in the Covid-19 era}

\author{
Cruz Garca Lirios $^{1^{*}}$ Jorge Hernndez Valds $^{1} \quad$ Margarita Jurez Njera $^{1}$ \\ ${ }^{1}$ Department of Social Work, Universidad Autnoma del Estado de Mxico (UAEMEX), Mxico
}

\section{Check for updates}

Correspondence to: Cruz Garca Lirios, Department of Social Work, Universidad Autnoma del Estado de Mxico (UAEMEX), Mxico;

E-mail: cgarcial@uaemex.mx

Received: October 30, 2021;

Accepted: November 29, 2021;

Published: December 2, 2021.

Citation: Lirios CG, Valds JH and Njera MJ. Review of social services on the vulnerable population in the Covid-19 era. Soc Work Soc Welf, 2021, 4(1): 172178.

https://doi.org/10.25082/SWSW.2022.01.001

Copyright: () 2022 Cruz Garca Lirios et al. This is an open access article distributed under the terms of the Creative Commons Attribution License, which permits unrestricted use, distribution, and reproduction in any medium, provided the original author and source are credited.

\section{(i) (8)}

\begin{abstract}
Meta-analytic studies are distinguished by comparing literature that reports positive effects with respect to literature that warns of spurious or negative effects. The aim of the present work was to establish the proportion of probabilities between categories and subcategories extracted from the consulted, updated and specialized literature. A documentary study was carried out with a selection of sources indexed to international repositories such as Copernicus, Dialnet, Ebsco, Latindex, Redalyc, Scielo. An indistinct scenario was found, even though the literature that reports positive effects on the quality of life and the subjective well-being of public health services prevails; suggesting the extension of the work to repositories like WOS and Scopus.
\end{abstract}

Keywords: Covid-19, social work, biopolitics, intervention, social welfare

\section{Introduction}

The history of the intervention of Social Work in the area of health has been built from a device that in the case of the Institutions of Higher Education, Social Sciences and Humanities this acquires a connotation of dispositivity in the Foucauldian sense of reproduction of social domination through the power of vigilance and punishment [1].

In this way, the present work is part of the Social Sciences division, Social Work discipline, subdiscipline of local development, but it can also be evaluated from the anthropology of power, sociology of violence or the psychology of conflict.

The objective of this paper is to establish the relationship between the proposed Foucault devices, the intervention of Social Work and Local Development from a review of 2010 to 2019 relative to the works published in repositories of Latin America - Copernicus, Dialnet, Ebsco, Latindex, Redalyc, Scielo, considering the keywords of "development", "Social Work", "device" and "intervention". In this sense, was discuss the scope and limits of the positivity device for the case of Social Work and its history of intervention in public health institutions.

The discussion will allow us to move towards a reconceptualization scenario in which we see an alternative intervention device that not only reproduces health policies, but also questions them in favor of the groups that are being violated [2].

\subsection{Dispositive academic positivity}

Foucault (1987) [3] links the concept of device to power and technology to account for a network of relationships between actors and institutions focused on the reproduction of social domination, although with emphasis on the sexual dimension in order to establish asymmetries between genders (p.29).

Consequently, the notion of device is linked to the advancement of information and communication technologies (ICTs), since the essence of the device is the espionage of the private sphere. As ICTs specialize, they register personalized information that will be disseminated and facilitate the governance of the individual and the groups in which he or she is inserted and wants to belong [4].

Once the State has established an inventory of the private sphere, then it can govern the public sphere in a more persuasive way without having to resort to the oppression of its praetorian, military or police institutions. This subtlety is the hallmark of the State and therefore of its device for reproducing the asymmetries between rulers and the governed [5].

Foucault (1987) [3] suggests that the sexual device advances until it becomes a device of subjectivity (p.94). The distinction is fundamental, because while in the pre-modern stage of humanity, the nascent State ruled with the truth to individuals, in the contemporary era of the 
State is intended control, vigilance and punishment of the truth, privileging the reproduction of power through conformity and obedience of the law.

If the device of power, sexual and subjective, is instrumented in the dissemination of information about a reality determined as truth by the State, then science has become an instrument of the rulers not only to establish differences with respect to the governed, but to reproduce those asymmetries through positivity [6] .

Foucault (2002) [7] proposes the positivity category to explain the pseudoscientific influence of disciplines and their instrumentation in the private sphere (page 299). The archeology of knowledge unmasks the disciplines that have usurped the scientific, hypothetical-deductive method to enroll in science and thereby ascribe to its institutionalization.

That is, the pseudoscientific positivity, as "statements that concern the similarities and differences between beings, their visible structure, their specific and generic characters, their possible classification, the discontinuities that separate them, and the transitions that link them." [7] warns the essence of the power device, namely: the pseudoscience applied to the reproduction of the social domination of rulers to the governed.

It is a stacking of theories, concepts, sentences and indicators that are presented as science, but without an identity with the social, even when this process is carried out with rigor and this is supported by the prestige of an academic community, the positivity is not scientificity, but rather pseudo-scientificity that cannot be according to the needs of a sector of civil society [7]

However, the power device is not only in the pseudoscience to reproduce the asymmetries between the actors. It is also observable in institutions that apply science closer to knowledge, medicine and psychology as examples [8]. In this sense, systematic observation is not only an inheritance of medicine, but also intervention with the purpose of modifying the course of personal micro-history, as well as the implementation of a distinctive institutional seal involves the instrumentation of the power device (p. 229).

If the surveillance and control device subjects those who violate the law, the disciplinary device limits the analysis to the positivity of a scientific tradition that reflects the power of the most advanced sciences on the pseudosciences that imitate them. The consequences of both devices, surveillance and control, on the intervention is not only the reproduction of the domination of rulers to their governed, but also the establishment of a legal and punitive sphere that punishes those who have exceeded the disciplinary limits [8].

In effect, pseudoscientific positivity does not contribute to the dialogue between political and social actors, but it conditions its asymmetries through discourses and enhances the vigilance of the rulers towards the governed in the same way that knowledge is guided by those who are imitated in their scientific procedures [9].

However, the devices not only operate in education or the private sphere, they also manifest themselves in the market through the establishment of a fair price, but in so far as it is established from the monitoring of inputs, supply and demand, he has lost its dimension of justice, since it does not reflect the time socially necessary for listing, but rather a police monetary control [10].

In the same way in which prices reach a true price through supply and demand, the other elements that are monitored by the State and determined by a discretionary price, will be free and may have a fair value that is the result of utility that a society attributes to him and not that imposed by his government [10].

Therefore, justice will be achieved by the State as soon as it stops monitoring and establishing a quotation which should be generated by supply and demand, through the natural freedom of a market in which the wills are not co-opted by the government. State [10].

In short, the power device, through its devices for monitoring and punishing sexuality, education and subjectivity it is built by a positivity that prevents the development of a morality of justice and rather encourages values of control and positivity that enhance the differences between those who govern and those who are governed. From these preliminary notions, the history of Social Work highlights health policies that were determining their periods, but also highlights events that were not controlled by the State and that allowed the reconceptualization of the discipline, as well as its adjustment to the needs of civil society.

\subsection{Brief history of social work intervention}

In a strict sense, the concept of Social Work underlies the Statute of Welfare when, in Germany, Prime Minister Bismark announces the implementation of benefits for workers in the industrial sector. In this way, the so-called social security was part of a social policy that aimed to encourage industrial production and ensure the availability of products according to the needs of the European industrial society with special attention to the nineteenth-century German society [11]. 
Social services, through social security programs and strategies were adopted in each of the European countries. Its emergence in the England of the 20th century generated socioeconomic studies for the establishment of priorities for the granting of resources among the working class. In this scenario Richmond was a pioneer in home visits and from this fact Social Work is considered as a discipline, since it stands out from charity and charity to be linked to the health sciences and behavior until then properly developed and recognized by public health institutions [12].

Very soon Social Work occupied an important place in the hospitals and health centers interested in registering the potential number of affiliates and beneficiaries with the policies of the Welfare State, as well as those organizations interested in promoting health.

The emergence of professions such as nursing and health psychology allowed Social Work to interact with very specific worldviews about health and lifestyles related to self-care, but to the extent that the Welfare state was questioned by the liberal currents were moving away from the decision making and precautionary principles of health risks.

In this way, social policies, in their area of public health, were dictated from the managerial and managerial elites of State institutions, avoiding the discoveries and contributions of health professionals regarding the inventory and documentation of civil actors at risk to your health.

Health policies that considered patients, beneficiaries or potential beneficiaries as passive subjects and dependent on specialized care, recognized the importance of homogenizing and specifying preventive campaigns in the most marginalized and violated sectors where the army of industrial reserves is reproduced. The capitalist economic system required in its gestation stage.

To the extent that public health campaigns were disseminated among the poorest sectors, they stopped the population explosion, but discouraged precautionary lifestyles and aimed at reducing health risks. It was not until the late 20th century that industries and organizations proposed hygiene standards and occupational health promotion when estimating losses due to accidents and illnesses in workplaces, as well as in those who earned less [13].

These events transformed again the function of Social Work that entered into a process of selfcriticism and self-questioning considered as a re-conceptualization. In the case of Mexico is not entirely clear when it took place and in what context, but in line with changes in health policies that stage of being used promoters and stage of targeting development strategies prevention that involved society in its self-care.

However, the deficits of financial resources for the case of unemployment or retirement determined a new policy of institutional evaluation and certification. In this new scenario, Social Work has developed models and devices with the purpose of highlighting its essence in terms of home visits, socioeconomic studies, registers and inventories of lifestyles and risk behaviors of marginalized sectors of civil society.

In short, the history of Social Work in relation to social policies, health programs, as well as prevention and promotion strategies, show three phases in which the discipline has become more important to the extent that it has systematized its functions, but above all, it has approached the vulnerable, marginalized and excluded sectors while the other professions are moving away [14]

However, during its history, the discipline influenced by public policies, had only considered these civil sectors as dependent. Now that the policies encourage the participation of citizens in order to prevent diseases and accidents that reduce their working life or compromise their abilities, Social Work is in the dilemma of reproducing the benefactor model, or adopting devices that allow the study of social sectors and anticipate participation scenarios in different economic, political and social spheres.

\subsection{Effects of social work intervention on health}

If health policies have been transformed in such a way that considers the individual as a key and factor even preponderant in the new public health system, then what adjustments are models of intervention focused on the passivity of the individual and control of the professionals, disseminated at the stage of the welfare state, but now require?

Power devices that reduced health rights and employment of workers to a specialized and conditioned by the resources and institutional capacities attention devices positivity 1 Social Work s Erian instruments rights management but guided by the prevention based on self-care lifestyles (see Table 1).

In this way, the positivity devices in the Social Work intervention guide civil participation, highlight the negotiation and consensus around the labor and occupational rights that health policies recognized from the high costs for care and the low costs aimed at prevention.

In the historical nomenclature of Foucault $[3,7,8,10]$ the devices are legitimized by the positivity of the sciences that imitate the hypothetico-deductive method with rigor and prestige, 
Table 1 Positive devices in the intervention of Social Work

\begin{tabular}{|c|c|c|}
\hline & Risks & Self-care \\
\hline Device & $\begin{array}{l}\text { The Stewardship of the State in matters of welfare centered its interest in the } \\
\text { policies of with regard to health, assuming that diseases and accidents are inherent } \\
\text { in Human Development. As a result, Social Work generated discourses and } \\
\text { strategies that disseminated homogeneous and focused health programs. }\end{array}$ & $\begin{array}{l}\text { Health policies encouraged adherence to treatments and re- } \\
\text { habilitation, but did not consider the importance of preven- } \\
\text { tion, reducing risk behavior and establishing occupational } \\
\text { safety protocols. }\end{array}$ \\
\hline Positivity & $\begin{array}{l}\text { The evaluation of the meanings that for the individual or the groups have the risks, } \\
\text { assumed as areas of opportunity for entrepreneurship and innovation, contributes } \\
\text { to a Local Development adjusted to the needs of people. }\end{array}$ & $\begin{array}{l}\text { It is represented as a banner of health and personal devel- } \\
\text { opment that, in addition to other cases, produces Local } \\
\text { Development. }\end{array}$ \\
\hline
\end{tabular}

Source: Prepared from the literature review

although without the identity or professional habitus required to dissuade opponents and persuade adherents to the system of social domination or differentiation between rulers and the governed.

The positivity or assertive implementation of the devices through speeches and strategies for monitoring and controlling self-care and adherence to treatment or rehabilitation reflects the asymmetries between those who make decisions and those who execute them. Strictly speaking, the positivity is an imitation of knowledge that were built in the institutions of public health.

From 1 to discipline of social work the device has been understood in a sense that more integration selectivity and exclusion [15]. Therefore, the intervention has been the guiding axis of the discipline's task. It has even defined the identity of the social worker, since this is not only the heir of charity, charity and altruism, but also the result of social exclusion indicated by suffering and vulnerability [16]. These are contexts in which disenchantment forged the identity of the social worker, making it more sensitive to the needs of sectors excluded from civil society [17].

The social issue of Social Work lies in the complexity that institutions cannot monitor and control through the reward or sanction of its members; professionals and beneficiaries [17]. It is more about establishing an interdisciplinary dialogue in which complexity can be studied and diagnosed as part of the social question. That is to say that the problems must be approached from a dialogic rather than from positivity.

In this way, the positive devices of the Social Work intervention can be substituted with the recognition of the other as interlocutor in the dialogue of knowledge that facilitates the understanding of the complexity of the social question.

\subsection{Specification of the model for the study of the effects of social services on the vulnerable population}

The specification of a model is necessary for the hypothesis contrast. It is a series of trajectories of relations between variables from empirically tested theoretical frameworks. Based on this consideration, the proposed model includes two constructs: literature A for the effects of public policies on quality of life and literature B for the effects of social programs on subjective well-being, with their indicators being the possible combinations between significant effects, spurious or negative of the political strategies of assistance on the vulnerable population [18].

The classical theories of public administration and social policies highlight the rector of the State as an organizer of public health and social assistance, but the new wave of institutional theories revalue the bureaucratic isomorphism as a factor that maximizes or reduces organizational health responses on biophysical and biophysical well-being. Even, new theoretical matrices that question the State and the public health institutions in charge of medical care warn a new governance in which the users distrust of the quality of the public service and the governmental action in the matter of prevention and promotion of the collective health.

\section{Methods}

A non-experimental, documentary, cross-sectional and exploratory study was carried out with a selection of indexed sources, with ISSN (International Standard Serial Number) and DOI (Digitall Object Identifier) records. The information was processed in a content analysis matrix of the academic discourse, the agenda of topics established around the key words and the framing of the discussion between the categories and the variables of "intervention" and "device". Next, a model was specified for the study of the effect of intervention devices in Local 
Development. Finally, its scope and limits are discussed with respect to other models specified and reported in the literature.

The data were processed considering the type of literature: A for sources that reported effects of the public health services on the quality of life of the groups affected; B for sources that reported effects of public services on wellbeing right holders.

A content analysis was carried out, considering the type A literature with a grade of 3 and the type B literature with 1. Expert judges in the topics rated synthetic extracts of the findings reported in three rounds of feedback in which the first grades were discussed and reconsidered by the participants until the differences are exhausted and consensus reached.

The data were processed in the QDA Miner version 4.0 qualitative analysis package, estimating the parameters of normality, contingency and correlation between the extracted data.

\section{Results}

Table 2 shows the non-parametric values that support the analysis of contingencies between categories $\mathrm{A}$ and $\mathrm{B}$ with respect to the informative extracts qualified by the expert judges.

Table 2 Descriptive data

\begin{tabular}{|c|c|c|c|c|c|c|c|c|c|c|c|}
\hline \multirow{2}{*}{$\mathrm{E}$} & \multirow{2}{*}{ M } & \multirow{2}{*}{$\mathrm{S}$} & \multirow{2}{*}{ W } & \multirow{2}{*}{$\mathrm{K}$} & \multirow{2}{*}{ A } & \multicolumn{3}{|c|}{$\mathrm{C} 1$} & \multicolumn{3}{|c|}{$\mathrm{C} 2$} \\
\hline & & & & & & $\mathrm{X}^{2}$ & $\mathrm{df}$ & $\mathrm{p}$ & $X^{2}$ & $\mathrm{df}$ & $\mathrm{P}$ \\
\hline \multicolumn{12}{|l|}{ R1 } \\
\hline e1 & 0.764 & 0.125 & 0.132 & 0.110 & 0.101 & & & & & & \\
\hline e2 & 0.619 & 0.109 & 0.172 & 0.143 & 0.103 & 13.24 & 14 & $<0.05$ & & & \\
\hline e3 & 0.562 & 0.180 & 0.191 & 0.189 & 0.104 & & & & & & \\
\hline e4 & 0.601 & 0.176 & 0.108 & 0.101 & 0.108 & & & & & & \\
\hline e5 & 0.782 & 0.160 & 0.167 & 0.162 & 0.109 & & & & & & \\
\hline e6 & 0.761 & 0.109 & 0.178 & 0.156 & 0.134 & & & & & & \\
\hline \multicolumn{12}{|l|}{$\mathrm{R} 2$} \\
\hline e1 & 0.629 & 0.156 & 0.143 & 0.108 & 0.167 & 14.23 & 13 & $<0.05$ & & & \\
\hline e2 & 0.641 & 0.174 & 0.162 & 0.173 & 0.134 & 13.25 & 19 & $<0.05$ & & & \\
\hline e3 & 0.673 & 0.152 & 0.183 & 0.162 & 0.142 & & & & 14.21 & 18 & $<0.05$ \\
\hline e4 & 0.693 & 0.145 & 0.103 & 0.151 & 0.161 & & & & & & \\
\hline e5 & 0.653 & 0.198 & 0.181 & 0.176 & 0.172 & & & & & & \\
\hline e6 & 0.782 & 0.143 & 0.176 & 0.182 & 0.109 & & & & & & \\
\hline \multicolumn{12}{|l|}{ R3 } \\
\hline e1 & 0.760 & 0.132 & 0.191 & 0.101 & 0.101 & 15.21 & 14 & $<0.05$ & & & \\
\hline e2 & 0.784 & 0.153 & 0.104 & 0.108 & 0.172 & 14.35 & 16 & $<0.05$ & & & \\
\hline e3 & 0.794 & 0.172 & 0.113 & 0.178 & 0.191 & 10.21 & 13 & $<0.05$ & & & \\
\hline e4 & 0.762 & 0.109 & 0.182 & 0.163 & 0.172 & & & & 13.21 & 12 & $<0.05$ \\
\hline e5 & 0.641 & 0.161 & 0.134 & 0.191 & 0.109 & & & & & & \\
\hline e6 & 0.781 & 0.189 & 0.196 & 0.145 & 0.102 & & & & & & \\
\hline
\end{tabular}

Source: Elaborated with data study. E = Extract: e1 = Positive Efects on Quality on Life, e2 = Negative Effects on Quality of Life, e3 = Spurious Efeccts on Quality on Life, e4 = Positive Efects on Wellbeing, e5 = Negative Effects on Wellbeing, e6 $=$ Spurious Efeccts on Weelbeing; $\mathrm{R}=$ Round, $\mathrm{M}=$ Mean, $\mathrm{S}=$ Standar Deviation, $\mathrm{W}=$ Sweddness, $\mathrm{K}=$ Kurtosis, $\mathrm{A}=$ Asimetry. $\mathrm{C}=$ Category; $\mathrm{C} 1=$ Literature $\mathrm{A}, \mathrm{C} 2=$ Literature $\mathrm{B}$

The structure of distribution and contingency suggest a proportional consensus higher in the first category relative to the literature that reports positive effects of social services on the quality of life and the subjective well-being of users, suggesting the observation of the structure of relationships between categories and informative extracts (see Table 3).

Table 3 Odds ratio

\begin{tabular}{ccccc}
\hline & e1 & e2 & e3 & e4 \\
\hline e1 & & & & \\
e2 & $0.328(0.1090 .781)$ & & & \\
e3 & $0.427(0.1290 .671)$ & $0.432(0.1230 .784)$ & & \\
e4 & $0.203(0.1090 .437)$ & $0.127(0.4320 .671)$ & $0.231(0.1090 .601)$ & \\
e5 & $0.321(0.1090 .562)$ & $0.324(0.1270 .439)$ & $0.146(0.0270 .712)$ & $0.321(0.2430 .456)$ \\
\hline
\end{tabular}

Source: Elaboration with data study. E = Extract: e1 = Positive Effects on Quality on Life, e2 = Negative Effects on Quality of Life, e3 = Spurious Effects on Quality on Life, e4 = Positive Effects on Wellbeing, e5 = Negative Effects on Wellbeing, e6 = Spurious Effects on Wellbeing. $\mathrm{C}=$ Category; $\mathrm{C} 1=$ Literature A, C2 = Literature B

The structure of the probability ratio shows a prevalence of the six types of literature and the findings that it reports, suggesting the observation of the structure of trajectories of relations between categories and extracts (see Figure 1). 


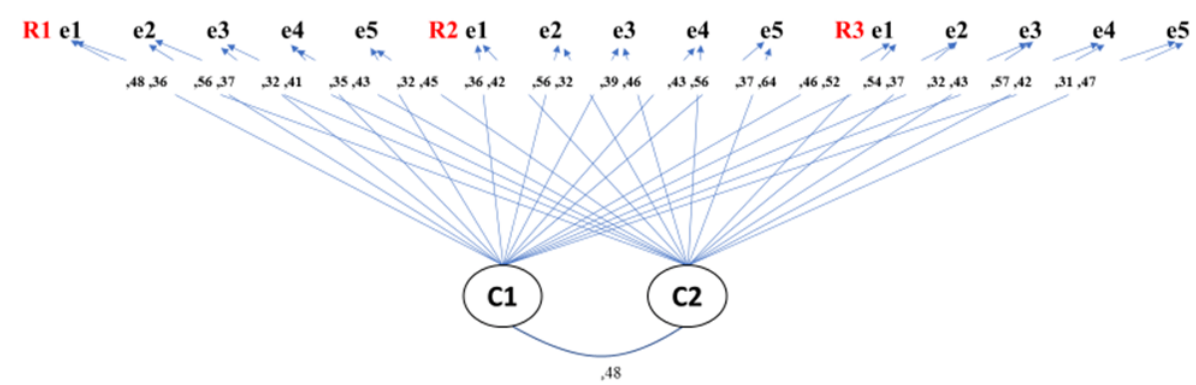

Source: Elaboration with data study. E = Extract: e1 = Positive Effects on Quality on Life, e2 = Negative Effects on Quality of Life, e3 = Spurious Effects on Quality on Life, e4 = Positive Effects on Wellbeing, e5 = Negative Effects on Wellbeing, e6 = Spurious Effects on Wellbeing. C = Category; $\mathrm{C} 1=$ Literature A, C2 = Literature B

Figure 1 Structural equation modelling

The structure of trajectories of proportions of probabilities among the six subcategories with respect to the two categories of the effects of social services on the quality of life and subjective well-being. A prevalence of the two categories is observed with respect to the six subcategories. That is, the literature consulted seems to warn that social services indistinctly affect negatively and positively the quality of life and subjective well-being.

\section{Discussion}

The contribution of the present work to the state of the question lies in the establishment of a model for the study of the indistinct effects of public health policies on the quality of life and the subjective well-being of the users reported in the literature consulted, but the design of the research limits the results to the research sample, suggesting the inclusion of repositories such as Web of Science or Elsevier.

The literature consulted on the effects of public health services on the quality of life and the subjunctive warn of an improvement trend based on social care, but in the present work indistinct proportions of probability have been demonstrated.

Such findings suggest the systematization of other sources from repositories such as WoS and Scopus, considering the biased tendency of positive reports, although an emergency of spurious effects is observed while the negative effects have not been reported to the same extent.

\section{Conclusion}

The objective of the present work was to establish the proportion of probabilities of the effects of health policies with respect to the quality of life and the well-being of the users, although the research design limited the findings to the research scenario suggesting the extension of the work to repositories like WOS and Scopus.

Regarding the incidence of results in health policies, the need for greater transparency in the publication of the spurious and negative effects of care systems, the quality of care and the evaluation of public services is appreciated.

\section{References}

[1] Llamas B, Nava S and Garcia C. Specification of a model of adherence to treatment. Ajayu, 2019, 17(1): $140-160$.

[2] Martnez E, Snchez A and Garca C. Governance of quality of life and wellbeing subjective. Ajayu, 2019, 17 (1): 121-139.

[3] Foucault M. Hermeneutics of the subject. Madrid: The Pickaxe, 1987.

[4] Garcia C. Dimensions of human development theory. Ehquidad, 2019, 11: 27-57. https://doi.org/10.15257/ehquidad.2019.0002

[5] Snchez A, Garca C, Juarez, M, et al. Effects of corporate governance policies on the quality of technological life. International Journal of Innovative Technology, 2019, 10(10): 1-14. https://doi.org/10.13140/RG.2.2.23394.58561

[6] Lopez S, Vilchis FJ, Delgado MA, et al. Specified model base on meaning related to climate and the institutional norm of workers in health center in Mexico. Ehquidad, 2019, 11: 11-25. https://doi.org/10.15257/ehquidad.2019.0001

[7] Foucault M. The archeology of knowledge. Buenos Aires: Siglo XXI, 2002. 
[8] Foucault M. Watch and punish. Buenos Aires: Siglo XXI, 2003.

[9] Rincn RM, Quintero ML, Coss J, et al. Meta Analityc Algorithm Structure of the Mobility Habitus. International Journal of Scientific Research, 2019, 1(1): 1-6. https://doi.org/10.13140/RG.2.2.11515.36644

[10] Foucault M. Birth of biopolitics. Mexico: FCE, 2007.

[11] Morales ML and Garcia C. Exploratory factorial modelling of the sanitary habitus. Annals of Heath, 2019, 1(1): 1-6. https://doi.org/10.13140/RG.2.2.10545.43365

[12] Ribeiro M, Lopez R and Mancinas S. Social work and social policy in Mexico. International Journal of Social Sciences and Humanities, 2007, 17(2): 175-200.

[13] Lpez E and Chaparro M. Labor competences of the social worker seen from the labor market. Tabula Rasa, 2006, 5: 261-293.

[14] Abreu MA. Social health work in primary health care. Nursing, 2009, 3 (2): 70-79.

[15] Carballeda AJ. The intervention in the social, exclusion and integration in the new social scenarios. Buenos Aires: Paids. 2004.

[16] Carballeda AJ. Social Work from a historical perspective focused on intervention. From the order of bodies to the outbreak of society. Buenos Aires: Paids. 2006.

[17] Carballeda AJ. The fragmented bodies. Social intervention in the scenarios of exclusion and disenchantment. Buenos Aires: Paids. 2008.

[18] Carreon J, Quintero ML, Molina HD, et al. Exploratory factor structure of the intention to migrate. Social Work Today, 2019, 87(1): 1-5. 